\title{
CAMP-specific PDE4 \\ phosphodiesterases and AIP in the pathogenesis of pituitary tumors
}

\author{
Graeme B Bolger1,2, Mariana F Bizzi33, Sergio V Pinheiro4, \\ Giampaolo Trivellin5, Lisa Smoot1, Mary-Ann Accavitti6, Márta Korbonits5,* \\ and Antonio Ribeiro-Oliveira Jr3,* \\ 'Department of Medicine, University of Alabama at Birmingham, Birmingham, Alabama, USA \\ 2Department of Pharmacology, University of Alabama at Birmingham, Birmingham, Alabama, USA \\ ${ }^{3}$ Department of Internal Medicine, Federal University of Minas Gerais, Belo Horizonte, Minas Gerais, Brazil \\ ${ }^{4}$ Department of Pediatrics, Federal University of Minas Gerais, Belo Horizonte, Minas Gerais, Brazil \\ ${ }^{5}$ Center for Endocrinology, William Harvey Research Institute, Barts and The London School of \\ Medicine, Queen Mary University of London, London, UK \\ ${ }^{6}$ Department of Microbiology and Immunology, University of Alabama at Birmingham, Birmingham, \\ Alabama, USA \\ *(M Korbonits and A Ribeiro-Oliveira Jr contributed equally to this work)
}

Correspondence should be addressed to $\mathrm{G} B$ Bolger Email gbbolger@uab.edu

\begin{abstract}
PDE4 cyclic nucleotide phosphodiesterases regulate CAMP abundance in cells and therefore regulate numerous processes, including cell growth and differentiation. The rat PDE4A5 isoform (human homolog PDE4A4) interacts with the AIP protein (also called XAP2 or ARA-9). Germline mutations in AIP occur in approximately $20 \%$ of patients with Familial Isolated Pituitary Adenoma (FIPA) and $20 \%$ of childhood-onset simplex somatotroph adenomas. We therefore examined the protein expression of PDE4A4 and the closely related isoform PDE4A8 in normal human pituitary tissue and in pituitary adenomas. PDE4A4 had low expression in normal pituitary but was significantly overexpressed in somatotroph, lactotroph, corticotroph and clinically nonfunctioning gonadotroph adenomas $(P<0.0001$ for all subtypes). Likewise, PDE4A8 was expressed in normal pituitary and was also significantly overexpressed in the adenoma subtypes $(P<0.0001$ for all). Among the different adenoma subtypes, corticotroph and lactotroph adenomas were the highest and lowest expressed for PDE4A4, respectively, whereas the opposite was observed for PDE4A8. Naturally occurring oncogenic variants in AIP were shown by a two-hybrid assay to disrupt the ability of AIP to interact with PDE4A5. A reverse two-hybrid screen identified numerous additional variants in the tetratricopeptide repeat (TPR) region of AIP that also disrupted its ability to interact with PDE4A5. The expression of PDE4A4 and PDE4A8 in normal pituitary, their increased expression in adenomatous pituitary cells where AIP is meant to participate, and the disruption of the PDE4A4-AIP interaction by AIP mutants may play a role in pituitary tumorigenesis.
\end{abstract}

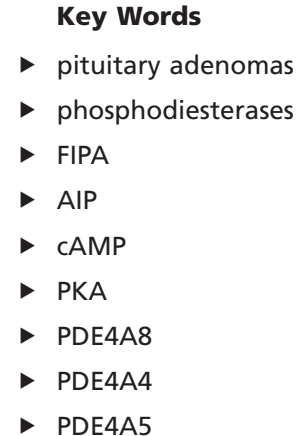

Endocrine-Related Cancer (2016) 23, 419-431

\section{Introduction}

The PDE4 enzymes are members of a large superfamily of cyclic nucleotide phosphodiesterases (PDEs) that enzymatically break down the 'second messengers' cAMP and/or cGMP and therefore regulate their abundance in cells (Bolger et al. 2007, Francis et al. 2011). cAMP signaling pathways, working through spatially distinct 
subpopulations of the cAMP effectors, the cAMPdependent protein kinase A (PKA) and the exchange protein activated by cAMP (Epac), differentially regulate a large range of distinct intracellular processes (Francis et al. 2011, Maurice et al. 2014). PDE4 enzymes are differentiated from other members of the PDE superfamily (PDE1 through PDE11, respectively), by their specificity for cAMP and by their ability to be inhibited by a class of highly selective inhibitors.

There are at least 20 different PDE4 isoforms in humans (Bolger 2007), which differ in their structure, pattern of expression in tissues and interactions with specific proteins. They are encoded by four genes (PDE $4 A$, $P D E 4 B, P D E 4 C$, and PDE4D), with additional diversity produced by alternative mRNA splicing and the use of promoters unique to each isoform (Bolger 2007, Bolger et al. 2007). PDE4A5 (known as PDE4A4 in humans) is a well-studied PDE4 isoform that interacts with several proteins and has a number of characteristic biochemical properties (Bolger et al. 1993, 1994, Christian et al. 2010). An important and apparently unique property of rat PDE4A5, compared with other rodent PDE4 isoforms, is that it interacts selectively with the AIP protein, a member of the immunophilin family of proteins (Bolger et al. $2003 b$ ). The AIP protein interacts with PDE4A5 largely through its tetratricopeptide (TPR) domain (Bolger et al. 2003b, Igreja et al. 2010, Morgan et al. 2012), which is a well-characterized protein-protein interaction domain found on many proteins (Kinoshita et al. 1990, Sikorski et al. 1990) and which is often disrupted in patients with AIP mutations (Igreja et al. 2010). The interaction of AIP with PDE4A5 changes the enzymatic activity of PDE4A5 and also its ability to be inhibited by PDE4-selective inhibitors (Bolger et al. 2003b).

Mutations in genes encoding components of cAMP pathways have been implicated in the predisposition to several endocrine neoplasms and related disorders (Stratakis 2013, for a review). Germline mutations in the gene encoding the regulatory subunit type $1-\alpha$ of PKA (PRKAR1A) produce the multiple neoplasia, myxoma and lentiginosis syndrome Carney complex (Horvath et al. 2010). Germline mutations in the PKA catalytic subunit can produce adrenal cortical adenomas (PRKACA), (Beuschlein et al. 2014) or Carney complex (PRKACB) (Forlino et al. 2014). Mosaic somatic mutations in the gene encoding the G-protein alpha subunit (GNAS), which regulates adenylyl cyclase, the enzyme that synthesizes cAMP, cause McCune-Albright syndrome, characterized by fibrous dysplasia of bone, café-au-lait nodules, and precocious puberty (Salpea \& Stratakis 2014), whereas somatic mutations can also be detected in $30-40 \%$ of somatotroph adenomas (Landis et al. 1989). Recently, microduplications in the G-protein-coupled orphan receptor GPR101, which activates adenylyl cyclase and therefore cAMP signaling, have been implicated in a disorder with very young-onset gigantism (Trivellin et al. 2014). These genetic syndromes implicate cAMP signaling in pituitary tumor pathogenesis and provide a rationale for study of additional cAMP signaling components in this process.

Germline mutations in the AIP gene are present in approximately $20 \%$ of patients with familial isolated pituitary adenoma (FIPA). The AIP mutation-positive patients have a characteristic clinical phenotype with usually young- or childhood-onset growth hormone (GH) and/or prolactin (PRL)-secreting adenomas and can be seen in cases with no apparent family history as well (Vierimaa et al. 2006, Daly et al. 2007, Leontiou et al. 2008, Heliovaara et al. 2009, Igreja et al. 2010, Gadelha et al. 2013, Beckers et al. 2013). AIP is expressed in the pituitary, and many pathogenic AIP variants block its interaction with PDE4A5 (Vierimaa et al. 2006, Leontiou et al. 2008, Igreja et al. 2010, Bolger et al. 2003b). Furthermore, impaired function of AIP in the pituitary attenuates cAMP signaling (Formosa et al. 2013, Formosa \& Vassallo 2014, Tuominen et al. 2015).

Given the role of both cAMP signaling and AIP in the pathogenesis of pituitary tumors, we wished to explore further the potential role of the PDE4A5-AIP interaction in pituitary tumorigenesis. Therefore, an important aim of the current studies was to demonstrate that PDE4A4 is expressed in normal pituitary and in pituitary adenomas, where it is available for interaction with AIP. We had shown previously that mRNA encoding PDE4A4 and its rat/mouse ortholog, PDE4A5, is expressed in a number of tissues, including the brain (Bolger et al. 1994, 1996), but there was no data on its expression in the pituitary. We have been particularly interested in the tissue-specific expression of PDE4A8, an isoform encoded by the PDE4A gene that has undergone rapid evolutionary change (Mackenzie et al. 2008). Human PDE4A8 differs from its rodent counterpart almost exclusively at its alternatively spliced amino-terminus and related $5^{\prime}$ genomic sequences, which are likely to control its tissue expression (Bolger et al. 1996, Mackenzie et al. 2008). Here we study PDE4A4 and PDE4A8 protein expression in normal pituitary and in pituitary adenomas using novel specific antibodies. We also identify additional variants in AIP that affect its ability to interact with PDE4A5.

Published by Bioscientifica Ltd. 


\section{Materials and methods}

\section{Tissue specimens}

Samples from pituitary adenomas were removed at transsphenoidal surgery. The tumor type was determined on the basis of clinical and biochemical findings before surgery and immunohistochemical determination of the expressed pituitary hormones: for the adenoma samples, all slides utilized showed more than $90 \%$ of the specific tumor, as confirmed by hematoxylin and eosin. Autopsy pituitary samples were collected within $24 \mathrm{~h}$ of death from patients with no evidence of any endocrine abnormality. Consecutive cuts were prepared for histological analysis from normal pituitary tissue and different types of pituitary adenomas. Informed consent was obtained from all pituitary patients, and the protocol was approved by the Institutional Research Ethics Committee.

\section{PDE4 antibodies}

The mouse monoclonal antibody 4A4-1, specific to human PDE4A4, was generated specifically for this study against the peptide sequence SAERAERERQPHRPIERADA (Fig. 1), corresponding to the unique amino-terminal region of PDE4A4 amino acids 51 through 70 in both human PDE4A4 (GenBank Accession number L20965.1) and rat PDE4A5 (GenBank L27057.1, Fig. 1) (Bolger et al. 1993, 1994, Mackenzie et al. 2008). The rabbit polyclonal antibody 7233 specific to human PDE4A8 was described previously (Mackenzie et al. 2008). The mouse monoclonal antibody 4E1.16, specific for human PDE4A8, was generated to the same peptide as the polyclonal antibody, of the sequence KGDERSRETPESDRAN, corresponding to the unique amino-terminal region of PDE4A8 (GenBank AY593872, (Mackenzie et al. 2008)). All monoclonal antibodies were purified by limiting dilution and then grown in culture. Antibodies were then purified from culture supernatants with a protein G-affinity matrix (Pierce, Thermo Fisher Scientific).

\section{Immunoblotting}

COS7 cells were transfected with the plasmid pcDNAN46VSV to express human PDE4A4, or with pcDNA4A8VSV to express human PDE4A8, or with vector pcDNA3 (Life Technologies), using methods that we have described previously (McPhee et al. 1999, Mackenzie et al. 2008, Christian et al. 2010). The proteins were engineered to contain a vesicular stomatitis virus (VSV) epitope at their carboxy terminus. Extracts from the cells were prepared using methods that we have described previously (McPhee et al. 1999, Mackenzie et al. 2008, Christian et al. 2010) and were analyzed by LDS-PAGE (Novex, Life Technologies) and immunoblotting with either an antibody to VSV (Sigma) (Kreis 1986) or the monoclonal antibody of interest.

\section{Human PDE4A4 and Rat PDE4A5, with AIP interaction sites}

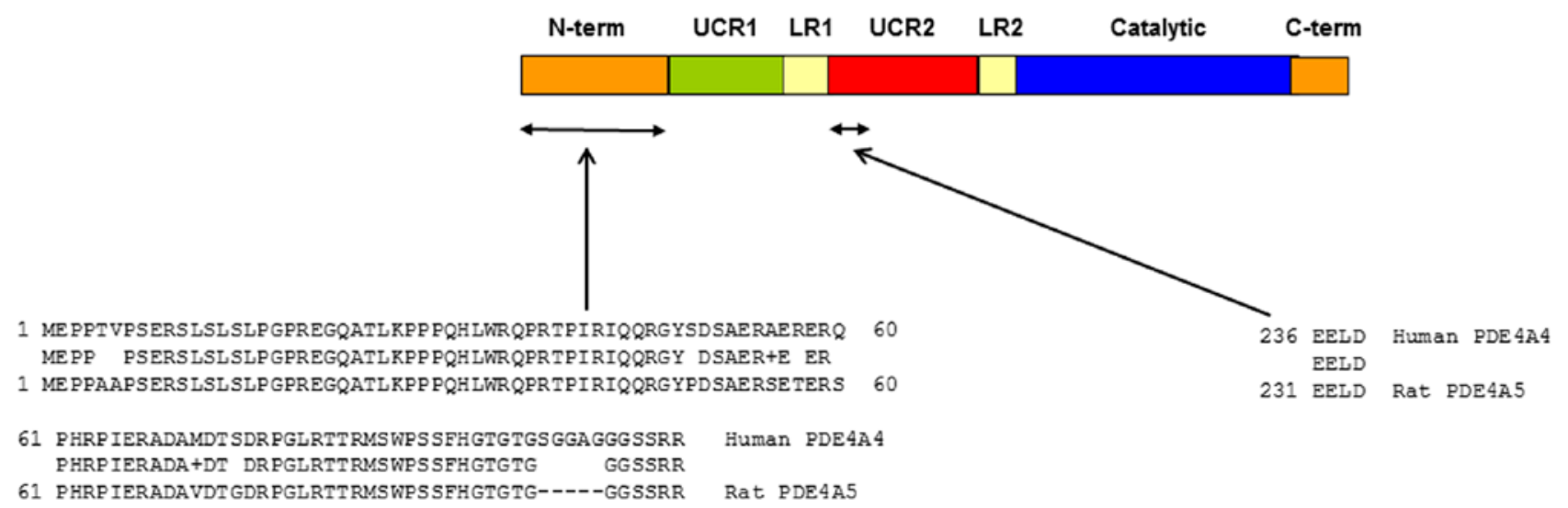

Figure 1

Human PDE4A4 and rat PDE4A5 with AIP interaction sites. Schematic representation of the human PDE4A4 protein structure. The human PDE4A4 consists of a unique amino-terminal region, upstream conserved regions 1 and 2 (UCR1 and UCR2) separated by linker regions 1 and 2 (LR1 andLR2), a catalytic domain, and the unique carboxyl-terminal region. The domain structure of rat PDE4A5 is identical. The amino acid sequences of the human PDE4A4 and rat PDE4A5 are shown on the specific regions implicated in the interaction of PDE4A5 with AIP: the unique N-terminal region and the EELD motif located at the beginning of UCR2. The middle row of amino acids shows the high identity of these conserved regions between the two species. The sequence SAERAERERQPHRPIERADA was used to generate a new PDE4A5/PDE4A4 antibody. 
For this purpose, samples were run in parallel lanes on the same gel and then transferred to a single filter. For immunoblotting, the filter was then cut in half, and each half was incubated with the appropriate antibody; after washing, the two halves were rejoined for image generation with enhanced chemiluminescence (ECL), generating a single image with both antibodies. Primary antibody incubations (1:500 for PDE4A4 and PDE4A8 and 1:5000 for VSV) were performed for $1 \mathrm{~h}$ in Tris-buffered saline with $0.1 \%$ Tween 20 , followed by two washes in the same buffer. Secondary antibody incubations (SC-5099, 1:10,000; Santa Cruz Biotechnology) were performed in the same buffer, followed by two washes in the same buffer. Signal development was with ECL (Pierce, Thermo Fisher Scientific).

\section{Immunofluorescent staining and confocal microscopy}

We performed confocal immunofluorescence analysis of somatotroph, corticotroph, lactotroph, and clinically nonfunctioning gonadotroph adenomas as well as normal pituitary tissue. Normal pituitary architecture was evaluated by reticulin staining. After deparaffinization and hydrating procedures, the slides were transferred into $400 \mathrm{~mL}$ of prewarmed $\left(94-96^{\circ} \mathrm{C}\right)$ target retrieval solution $(40 \mathrm{~mL}$ of stock into $360 \mathrm{~mL}$ water; Dako) in a glass container in a water bath. The sections were incubated in blocking solution (1\% BSA and $0.1 \%$ Tween 20) at room temperature for $1 \mathrm{~h}$ and then incubated overnight at $4^{\circ} \mathrm{C}$ with one of the primary antibodies. The mouse monoclonal antibody 4A4-1 was used for all PDE4A4 comparisons, whereas the mouse monoclonal $4 \mathrm{E} 1.16$ was used for all PDE4A8 comparisons. In order to colocalize the selected proteins in different cells, polyclonal goat anti-GH (L20, 1:50; Santa Cruz Biotechnology), polyclonal goat anti-ACTH (P-12, 1:50; Santa Cruz Biotechnology), polyclonal rabbit anti-follicle-stimulating hormone (FSH) (87461:25; Abcam) or polyclonal mouse anti-FSH (C10, 1:25; Dako), and polyclonal goat anti-PRL (C-17, 1:50; Santa Cruz Biotechnology) or polyclonal rabbit anti-PRL (1:50; Dako), with one of the PDE4A4- or PDE4A8-specific antibodies described previously, were also added to the incubation buffer. After an overnight incubation, slides were rinsed five times in PBS and then incubated for $1 \mathrm{~h}$ in the dark at room temperature with antigoat Alexa 546 (1:100; Life Technologies), anti-rabbit Alexa 546 (1:50, 1:100, or 1:200; Life Technologies), anti-mouse DyLight 488 (1:50, 1:200, or 1:400; Pierce, Thermo Fisher Scientific), anti-goat Alexa 488 (1:100; Life Technologies) or anti-mouse Alexa 546 (1:200; Life Technologies), according to the primary antibodies previously used. Due to a change of PRL antibody used in our university hospital from goat to rabbit anti-PRL, secondary antibodies used in PRL experiments for the isoform PD4A8 had to be altered in order to reach the expected double labeling. Following washes with PBS, sections were mounted in $90 \%$ glycerol $/ 10 \%$ Tris $1 \mathrm{M}$, and images were captured through confocal microscope (Leica TCS SP5; Leica), 63× objective, and $630 \times$ original magnification. All confocal settings were determined at the beginning of the imaging session and remained unchanged. For quantitative analysis, images were captured at 8 bits and analyzed in gray scale, using the protocol we have published previously (Ribeiro-Oliveira Jr et al. 2008). Briefly, three different normal pituitary samples and four to seven distinct samples of each adenoma subtype were analyzed. Three to four images were captured randomly from each sample and three measurements were obtained for each image, with about 30-50 cells also chosen randomly in each analyzed sample. ImageJ (the National Institutes of Health, Bethesda, MD, USA) software was used to quantify fluorescence intensity and area intensity, as well as the area of each individual cell. The background fluorescence and the energy intensity threshold were then subtracted from the region of interest in the same level for all examined pictures. The relative fluorescence corresponded to the unit 'gray level', varying from 0 (black) to 255 (white), as an average of the area for each cell (the sum of gray value of all pixels divided by the number of pixels/area).

\section{Two-hybrid analysis of protein-protein interactions}

The effect of variants in AIP on its interaction with PDE4A5 was studied by the yeast two-hybrid system, as described previously (Bolger et al. 2003b, Leontiou et al. 2008, Igreja et al. 2010). For these studies, PDE4A5 was cloned into the NotI-site of pLEXAN, to generate a LexA DNA-binding domain fusion (i.e., the plasmid pLEXAR6). Wild-type (WT) AIP and various missense AIP sequence variants were cloned into the NotI-site of pGADN, to generate GAL4 activation domain fusions (i.e., the plasmid pGADNRB3 and mutants thereof). Site-directed mutagenesis was performed using the circular mutagenesis method (Weiner et al. 1994), and all mutants were verified by sequencing before use. Quantitative $\beta$-galactosidase assays were performed in the Saccharomyces cerevisiae strain L40 by the method of Guarente (Guarente $1983)$ using $O$-nitrophenyl- $\beta$-D-galactopyranoside as a substrate. Each variant was tested in at least two different yeast clones.

Published by Bioscientifica Ltd. 


\section{'Reverse' two-hybrid analysis}

This was performed essentially as we have described previously for a different interaction (Steele et al. 2001). The plasmid pGADNRB3Sma was generated by site-directed mutagenesis of pGADNRB3. It encodes the full open reading frame of AIP, cloned into the NotI site of pGADN (Bolger et al. 2003b), with a SmaI site engineered at codon 168. The generation of this site created a variant (W168G) in AIP that had no effect on its ability to interact with PDE4A5 in two-hybrid assays (data not shown). To mutagenize the AIP TPR homology region (Bolger et al. 2003b), PCR primers were synthesized that amplified codons $168-330$ of AIP, with some vector sequences at the 3 ' end of the insert. The PCR product overlapped approximately 30 nucleotides at each end with SmaI-cut pGADNRB3Sma DNA. Therefore, cotransformation of $S$. cerevisiae L40 with the PCR product and SmaI-cut pGADNRB3Sma1 DNA efficiently generated full-length GADNRB3Sma with PCR-generated AIP TPRs, by the use of recombination in vivo. The PCRs were designed to introduce a single-nucleotide substitution, on average, in the PCR product and used $25 \mathrm{U} / \mathrm{mL}$ of Taq DNA Polymerase (Thermo Fisher Scientific) in $20 \mathrm{mM}$ Tris- $\mathrm{HCl} \mathrm{pH}$ 8.4, $50 \mathrm{mM} \mathrm{KCl}, 5 \mathrm{mM} \mathrm{MgCl} 2,0.2 \mathrm{mM}$ dATP, $0.4 \mathrm{mM}$ of each of dCTP, dTTP, and dGTP, $1 \mu \mathrm{g} / \mathrm{mL}$ of pGADNRB3Sma and each PCR primer at $1 \mathrm{nM} / \mathrm{mL}$. Ten separate PCRs, each $100 \mu \mathrm{L}$, were performed for 25 cycles with an annealing temperature of $55^{\circ} \mathrm{C}$. The PCR products were pooled and $20 \mu \mathrm{L}$ were mixed with $50 \mathrm{ng}$ of SmaI-cut pGADNRB3Sma DNA and transformed into S. cerevisiae strain L40 containing pLEXAR6. Colonies containing both plasmids were selected by their ability to grow in the absence of tryptophan and leucine, replica-plated onto nylon filters, and subjected to a filter $\beta$-galactosidase assay (Bolger 1998). The pGADNRB3Sma mutant plasmids were isolated from white colonies (i.e., those lacking $\beta$-galactosidase activity) by their ability to complement the leuB-genotype of Escherichia coli strain LB101. The PCR-generated region of the resulting plasmids was then sequenced with an ABI 3700 sequencer (Applied Biosystems).

\section{Characterization of AIP variants}

Three public databases were interrogated to check for the allele frequencies of the AIP variants tested in this study: the 1000 Genomes Project (Abecasis et al. 2012); the Exome Variant Server (EVS), NHLBI GO Exome Sequencing Project (ESP), Seattle, WA, USA (http://evs.gs.washington.edu/EVS/) (accessed on March 2016); and the Exome Aggregation Consortium (ExAC), Cambridge, MA, USA (http://exac. broadinstitute.org (accessed on 1 March 2016)).

\section{Statistical analysis}

Variables were first checked for normal distribution through the Shapiro-Wilk test. The immunofluorescence data comparing each adenoma subtype with normal pituitary tissue were tested for statistical significance with the nonparametric Mann-Whitney $U$ test, using GraphPad Prism 6.0 (GraphPad). Different adenoma subtypes were compared through Kruskal-Wallis followed by Dunn's multiple comparisons test. Quantitative $\beta$-galactosidase assays were analyzed by unpaired $t$-test (SigmaPlot; Systat, San Diego, CA, USA). Significance was taken as $P<0.05$. Data are shown as mean \pm S.E.M. or S.D.

\section{Results}

\section{PDE4A4 is specifically expressed in pituitary adenomas}

As the rodent homolog of PDE4A4 interacts with AIP (Bolger et al. 2003b), we wished to determine PDE4A4 distribution in normal human pituitary cells and adenomas (Fig. 2). For this study, we developed a monoclonal antibody, 4A4-1, specific for PDE4A4 (and also PDE4A5). Immunoblotting of protein extracted from cells transfected with PDE4A4 shows a band with a relative molecular mobility of $125 \pm 3 \mathrm{kDa}$, as shown previously (Mackenzie et al. 2008). Immunofluorescence of normal pituitary showed that PDE4A4 is present in GH and FSH cells, with very low expression in PRL or ACTH cells. However, we detected a significantly higher expression of PDE4A4 in GH-, PRL- or ACTH-secreting pituitary adenomas, as well as FSH-positive non-functioning pituitary adenomas (NFPAs), compared with the corresponding cell type in normal pituitary (Fig. 2). By contrast, we did not see any expression in fat tissue, which was used here as a negative control.

\section{PDE4A8 is expressed in normal pituitary cells and adenomas}

We had previously developed a polyclonal antibody to PDE4A8 and used it to demonstrate its expression in several regions of the CNS (Mackenzie et al. 2008). For this study, we have developed a monoclonal antibody, 4E1.16, which has the same specificity as the polyclonal antibody (see 'Materials and methods' section for details) and used immunofluorescence to determine its expression in pituitary tissue (Fig. 3). The 4E1.16 antibody detected a protein of the correct size on immunoblotting of cells transfected to express PDE4A8.

Published by Bioscientifica Ltd 
A

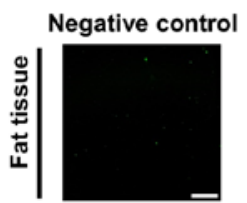

B

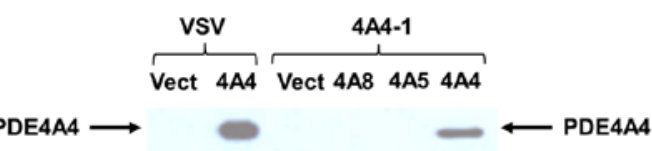

C
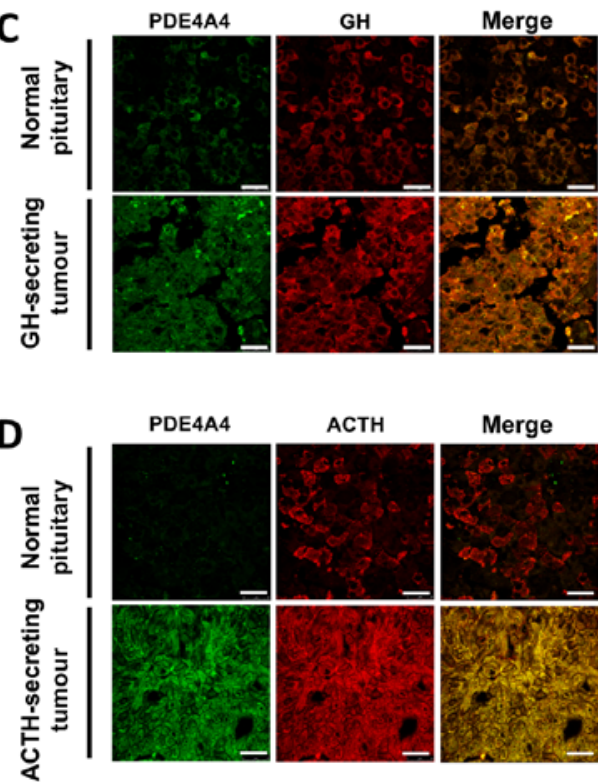

E
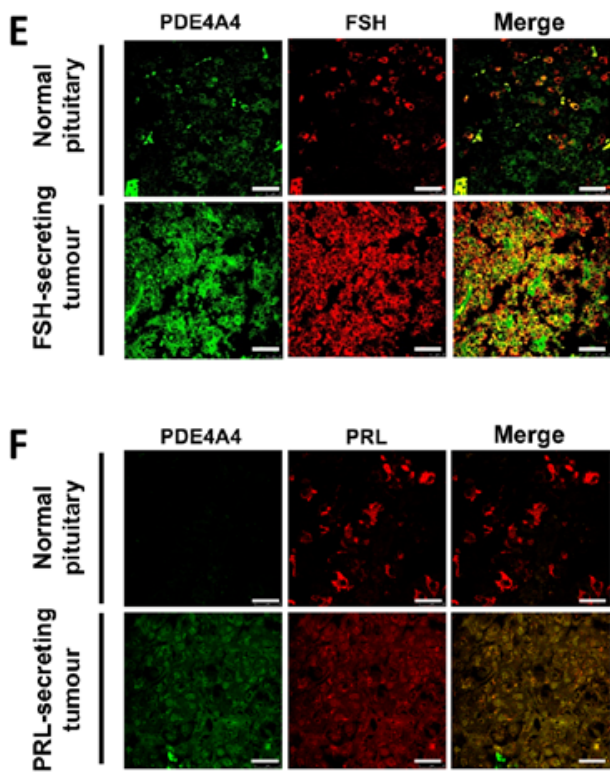
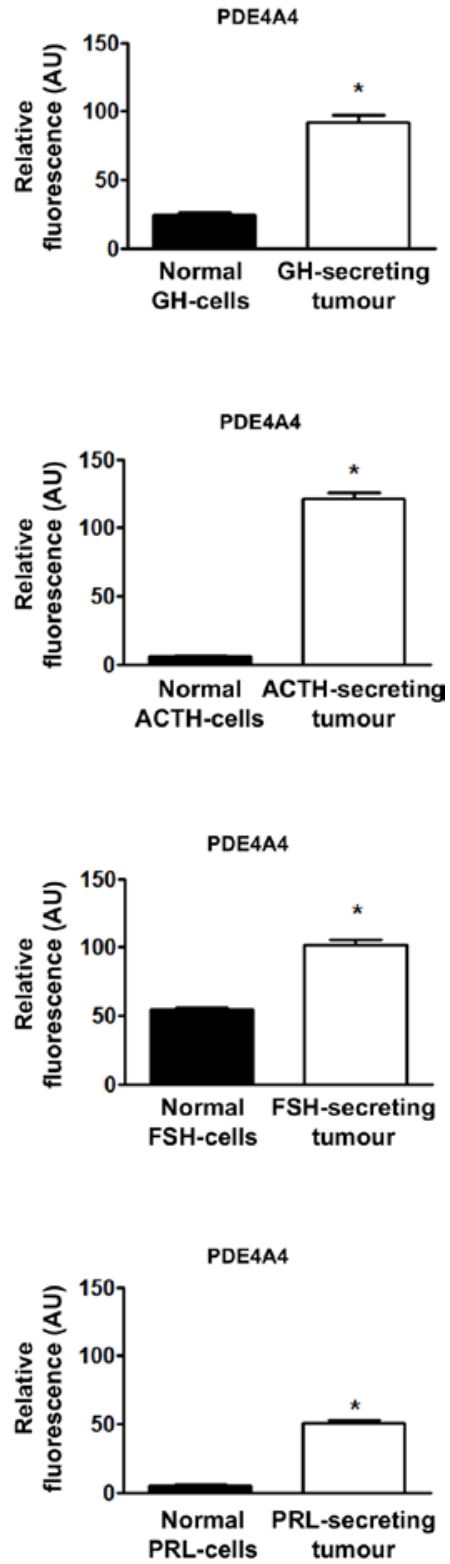

Figure 2

Localization of PDE4A4 in the pituitary. (A) Immunofluorescence with the 4A4-1 antibody in fat tissue, as a negative control. (B)

Immunoblotting with the 4A4-1 antibody. COS7 cells were transfected to express human PDE4A4 (4A4) or vector (Vect). All PDE constructs also encoded a VSV epitope at the carboxyl-terminus of the protein. LDS-PAGE and immunoblotting with an antibody against VSV, or with 4A4-1, were performed as described in the 'Materials and methods' section. The PDE4A4 protein migrated at $97 \mathrm{kDa}$. (C, D, E and F) Double immunofluorescent staining using monoclonal 4A4-1 (green staining) and polyclonal GH, ACTH, FSH, or PRL (red staining) antibodies in normal pituitary $(N=3)$, and in GH-, ACTH-, FSH- (NFPA), and PRL-secreting adenomas $(N=4-7$ for each adenoma subtype; $C, D, E$, and F, respectively). The bar graphs to the right of each panel provide semiquantitation of the relative fluorescence of PDE4A4 in each adenoma type, compared with its respective normal cell. Scale bar $=25 \mu \mathrm{m}$. All data are shown as mean \pm S.E.M.; $\mathrm{AU}$, arbitrary units; ${ }^{*} P<0.0001$.
Immunofluorescence of normal pituitary showed that PDE4A8 was present in all cell types, with somewhat lower expression in ACTH cells. In pituitary adenomas, PDE4A8 was expressed at significantly higher levels, in all subtypes (Fig. 3). We did not see any expression of PDE4A8 with this antibody in control tissues, such as fat tissue, consistent with results obtained previously with the polyclonal antibody (Mackenzie et al. 2008).

\section{Differences among different adenoma subtypes for PDE4A4 and PDE4A8}

When different adenoma subtypes were compared for PDE4A4 (Fig. 4A), this isoform was significantly reduced in prolactinomas compared with the other adenoma subtypes (Fig. 4A). However, PDE4A4 abundance in corticotrophinomas was significantly

Published by Bioscientifica Ltd 
A

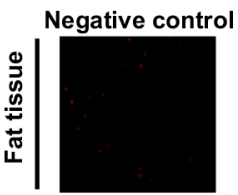

B

B

PDE4A8 $\overbrace{\text { Tx } \quad \text { Vect Tx Vect } \quad \text { P1 } \quad \text { P2 }}^{\text {VSV }}$

$\begin{array}{llll}\text { Tx } & \text { Vect Tx Vect } & \text { P1 } & \text { P2 }\end{array}$
PDE4A8
C

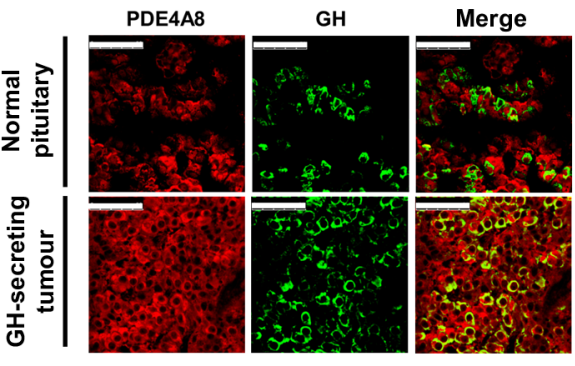

D

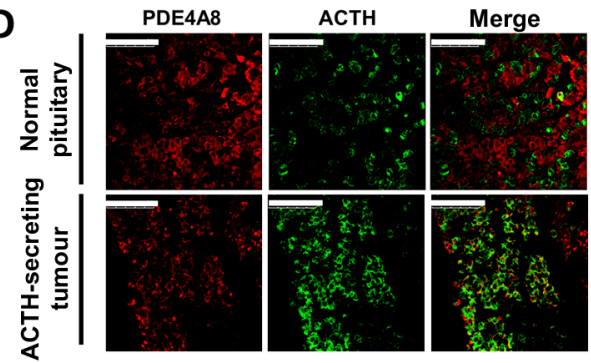

E

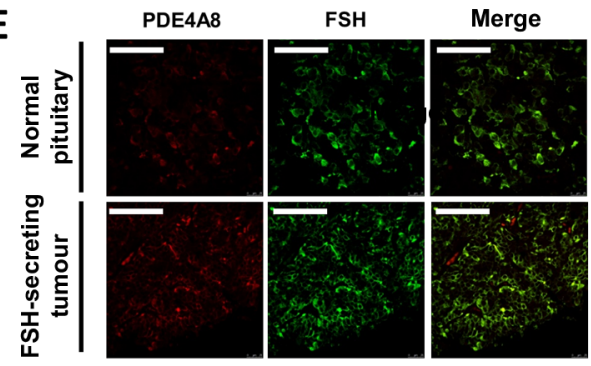

$\mathbf{F}$

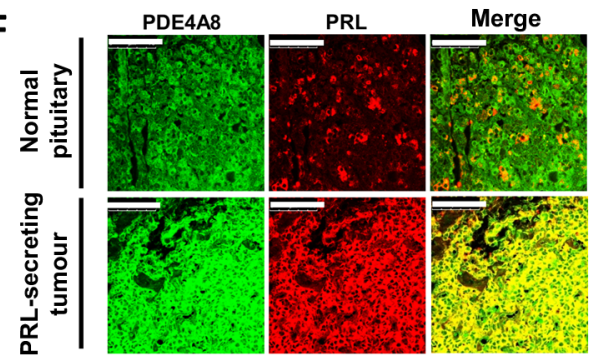

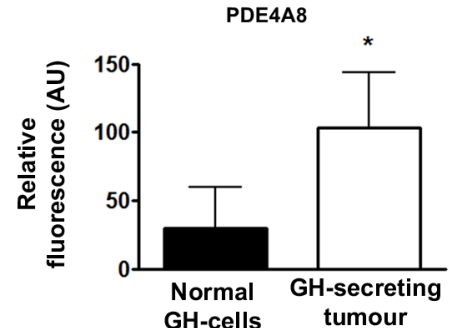

PDE4A8

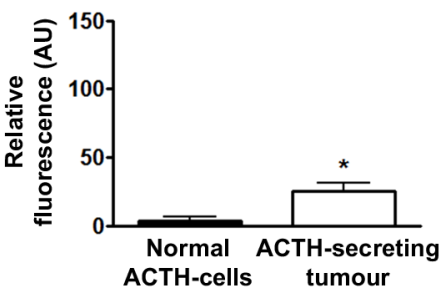

PDE4A8

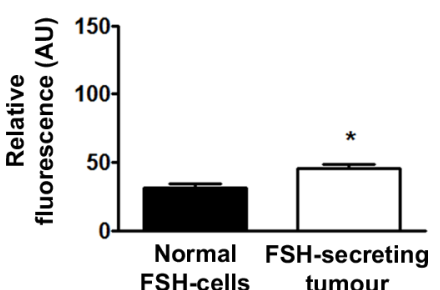

PDE4A8

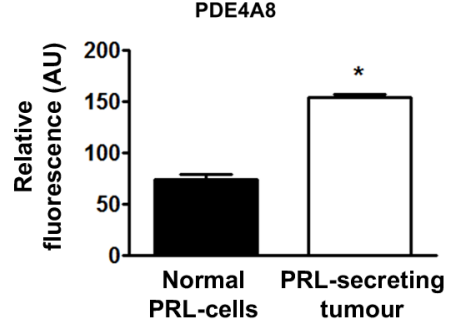

Figure 3

Localization of PDE4A8 in the pituitary. (A) Immunofluorescence with the 4E1.16 antibody in fat tissue, as a negative control. (B)

Immunoblotting with the 4E1.16 antibody. Extracts from COS7 cells transfected to express PDE4A8-VSV or with vector (Vect) were immunoblotted with an antibody against VSV or with 4E1.16. On separate gels, PDE4A8-VSV extracts were immunoblotted with 4E1.16 and the peptide used as immunogen (P1), or an unrelated peptide (P2). All methods were otherwise as for Fig. 2B. The PDE4A8 protein migrated at $102 \mathrm{kDa}$. (C, D and E) Double immunofluorescent staining using monoclonal 4E1.16 (red staining) and polyclonal GH, ACTH, and FSH (green staining) antibodies in normal pituitary $(\mathrm{N}=3)$ and $\mathrm{GH}$ - and ACTH-secreting adenomas and NFPAs ( $N=4-7$ for each adenoma subtype; $C, D$, and $E$, respectively). (F) Double immunofluorescent staining using monoclonal 4E1.16 (green staining) and polyclonal PRL (red staining) in normal pituitary $(N=3)$ and PRL-secreting adenomas $(N=5)$. The bar graphs to the right of each panel provide quantitation of the relative fluorescence of PDE4A8 in each adenoma type, compared with its respective normal cell. Scale bar $=75 \mu \mathrm{m}$. All data are shown as mean \pm S.E.M.; $\mathrm{AU}$, arbitrary units; ${ }^{*} P<0.0001$. increased compared with the other adenoma subtypes (Fig. 4A).

For the PDE4A8 isoform, in turn, prolactinomas showed significantly higher PD4A8 expression than the other adenoma subtypes (Fig. 4B), whereas corticotrophinomas showed the lowest abundance of PDE4A8 (Fig. 4B).
Disease-associated variants in AIP attenuate its interaction with PDE4A5

AIP interacts specifically with PDE4A5 (Bolger et al. $2003 b$ ) and mutations in AIP that are associated with FIPA attenuate this interaction (Leontiou et al. 2008, Igreja et al. 2010). A yeast two-hybrid quantitative $\beta$-galactosidase assay can rapidly and conveniently assess the effects of

Published by Bioscientifica Ltd. 
A

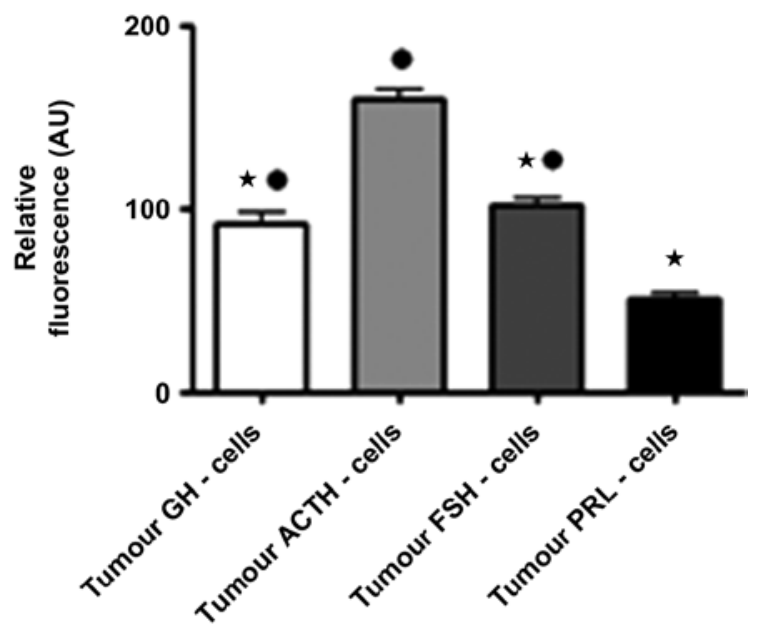

B

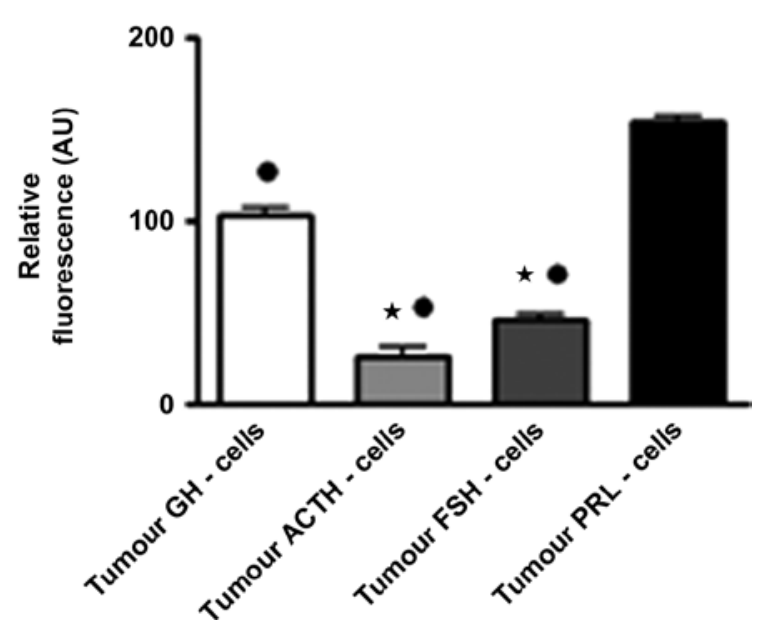

Figure 4

Comparison of PDE4A4 and PDE4A8 immunostaining in pituitary adenomas. (A) PDE4A4 expression in pituitary adenoma subtypes. All data are shown as mean \pm S.E.M.; $A U$, arbitrary units; ${ }^{*} P<0.0001$ compared with corticotroph adenomas and $P<0.0001$ compared with lactotroph adenomas. (B) PDE4A8 expression in pituitary adenoma subtypes. All data are shown as mean \pm S.E.M.; $A U$, arbitrary units; ${ }^{*} P<0.0001$ compared with corticotroph adenomas and $\bullet P<0.0001$ compared with lactotroph adenomas.

$A I P$ variants on its interaction with PDE4A5, which in turn can inform about the possible pathogenicity of $A I P$ variants. In this study, we analyzed/reanalyzed a large number of disease-associated AIP variants, including six variants that we have not reported with this assay previously (Leontiou et al. 2008, Igreja et al. 2010), and found that attenuation of interaction generally correlated with the disease phenotype (Fig. 5). The new and previously studied single amino acid substitutions or deletions (C238Y, R271W, Y248del, and V291M) and the truncation mutations (R81*, Q164*, Q217*, and R304*), all of which are strongly disease associated, completely ablate the interaction (Fig. 5). We also saw ablation, but with borderline statistical significance, by the K241E and R304Q missense variants, which are also felt to be disease associated. The I257V and A299V variants, which are predicted to be unlikely to be pathogenic and have uncertain clinical significance, showed no clear difference. Conversely, the R16H and V49M missense variants, which are generally considered to be rare SNPs (Igreja et al. 2010), and are located outside the TPRs, have no effect, or have only a weak effect on the interaction (Fig. 5). Two apparently disease-causing variants, K103R and $\Delta \mathrm{G} 23 / \mathrm{E} 24$, have no clear inhibitory effect or may augment the interaction, as measured by this assay (Fig. 5). K103R is, however, a conservative substitution, and both K103R and $\Delta$ G23/E24 are located outside the TPRs, which are considered to mediate its interaction with PDE4A5 (Table 1).

\section{Isolation of additional variants in the AIP TPRs}

The AIP TPRs form a close association with two different regions of PDE4A5 (Bolger et al. 2003b). Given this close association, it seems unlikely that all the amino acids in the TPRs that are essential for this interaction have been identified in the analyses performed to date. These amino acids would also be potential sites of disease-associated variants. To identify such amino acids, we performed random mutagenesis of the AIP TPRs and then used twohybrid approaches to select and identify variants that attenuated the AIP-PDE4A5 interaction. This approach, typically called 'reverse two-hybrid', has successfully been used to characterize many protein-protein interactions. With this screen, we identified seven single amino acid variants (K175E, C208R, N236H, C254R, H275L, L306P and L309P) and one double variant (W223R/V250A) in the AIP TPRs that strongly attenuated their ability to interact with PDE4A5 (Fig. 5). Intriguingly, one of these variants, C254R, has been recently identified as a disease-associated mutation in a patient with gigantism: this female patient was diagnosed at the age of 14 years due to tall stature $(184 \mathrm{~cm}$, midparental height $161.5 \mathrm{~cm})$ and primary amenorrhea and had a large $(46 \times 44 \times 31 \mathrm{~mm}) \mathrm{GH}-$ and PRL-secreting macroadenomas causing hydrocephalus. Insulin-like growth factor 1 (IGF-1) was $5 \times$ and PRL was

Published by Bioscientifica Ltd. 

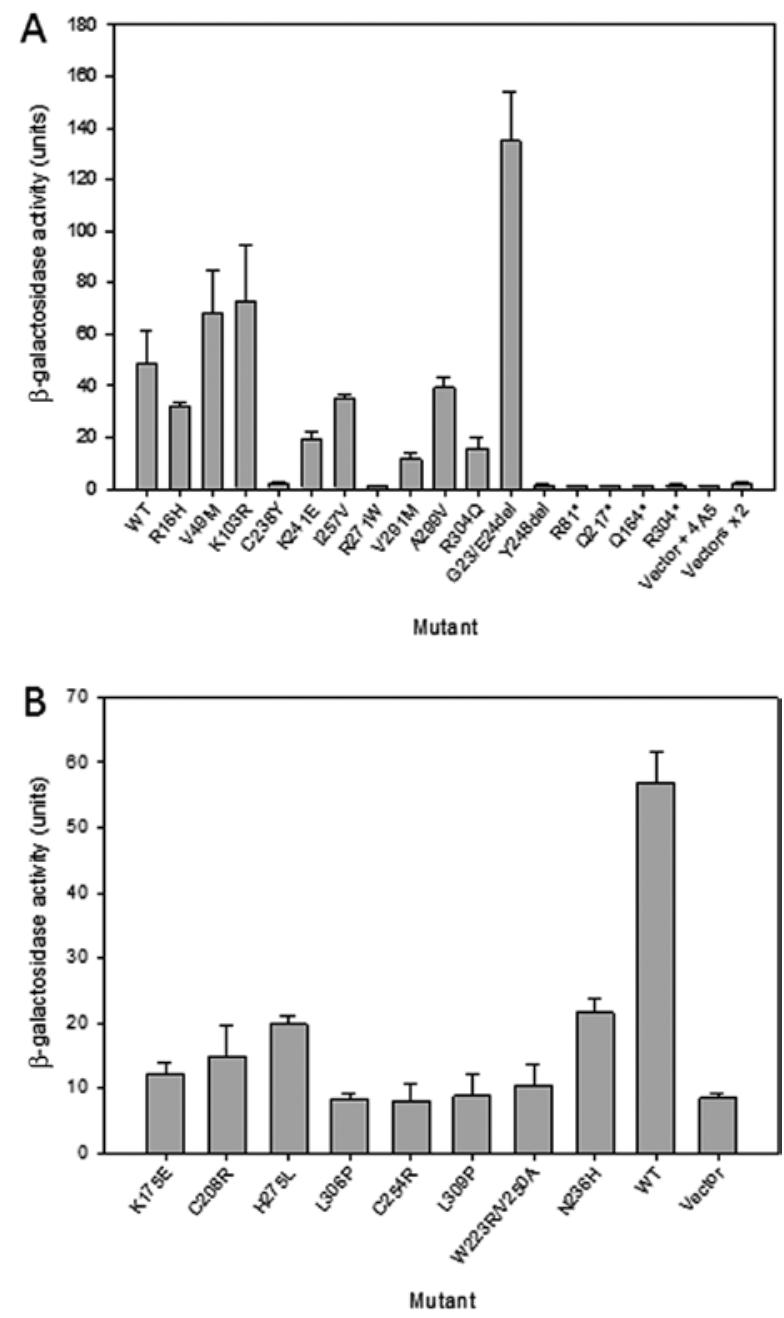

Figure 5

(A) Yeast two-hybrid quantitative $\beta$-galactosidase assay of human AIP mutants. AIP mutants were expressed in yeast cells, and their effect on AIP interaction with PDE4A5 was measured with a yeast two-hybrid quantitative $\beta$-galactosidase assay. Variants not studied previously are indicated in bold type in this figure legend; selected previously studied variants are included for comparison. A significant reduction in $\beta$-galactosidase activity ( $0-30 \%$ of WT; $P<0.03$ by $t$-test) was observed for missense variants C238Y, R271W, V291M, and Y248del, as well as for all the truncation mutations tested (R81*, Q217*, Q164*, and R304*). The K241E and R304Q mutants were of borderline significance $(P=0.062)$. The $\mathrm{R} 16 \mathrm{H}$, V49M, K103R, I257V, and A299V variants show activity $33-100 \%$ of WT (less than three-fold difference; $P=$ not significant (NS)) from WT AIP. Substantial increased activity is seen with the G23/E24 deletion $(P=0.011)$. Each variant was tested in at least two different yeast clones, with identical results ( $N=3$ for each clone). Mean \pm s.D. are shown for each mutant. Vector+4A5: PDE4A5 with the AD vector with no insert; Vectors $X$ 2: both vectors with no insert. (B) Yeast two-hybrid quantitative $\beta$-galactosidase assay of AIP mutants identified in a reverse two-hybrid screen. AIP mutants identified in a reverse two-hybrid screen were expressed in yeast cells, and their effect on AIPs interaction with PDE4A5 was measured with a yeast two-hybrid quantitative $\beta$-galactosidase assay, as in panel A. All mutants showed a significant reduction in $\beta$-galactosidase activity $(0-30 \%$ of WT; $P<0.03$ by $t$-test). Each variant was tested in at least two different yeast clones, with identical results ( $N=3$ for each clone). Mean \pm S.D. are shown for each mutant. Vector: PDE4A5 with the AD vector with no insert.
150× upper limit of normal (Hernandez-Ramirez et al. 2015b, Iacovazzo et al. 2015).

Because of technical issues with the two-hybrid system, in that PDE4A8 tends to have intrinsic transactivation activity, detectable in several different two-hybrid vector/ host systems, we have been unable to assess the effects of AIP variants on its interaction, if any, with PDE4A8.

\section{Discussion}

PDE4s play an essential role in cAMP signaling in many organs and tissues (Bolger et al. 2007, Conti \& Beavo 2007, Houslay 2010, Francis et al. 2011, Maurice et al. 2014), in that they catalyze the breakdown of cAMP to AMP and therefore contribute to the regulation of cAMP levels in cells. cAMP is generated by adenylyl cyclases, which, in majority of cell types, including pituitary, are regulated by several stimuli, including G-protein-coupled receptors (GPCRs), calcium fluxes, and phosphorylation by a number of kinases (Willoughby \& Cooper 2007). cAMP activates two downstream effectors, PKA and Epac, and PKA phosphorylates numerous substrates, which in turn reflect its protean physiologic functions in cells. GPCRs, cyclases, PKA, and PDEs are often found to be physically colocalized in cells and therefore regulate cAMP levels in specific subcellular compartments (Conti \& Beavo 2007, Bolger et al. 2007, Willoughby \& Cooper 2007, Houslay 2010, Francis et al. 2011, Maurice et al. 2014). The presence and/or activity of PDE4 isoforms in these compartments may be regulated, at least in part, by specific protein-protein interactions; for example, the PDE4D5 isoform interacts selectively with RACK1 and $\beta$-arrestin2 (Yarwood et al. 1999, Perry et al. 2002, Bolger et al. 2003a) and the PDE4A5 isoform (called PDE4A4 in humans) selectively interacts with AIP (Bolger et al. $2003 b$ ). The expression of cAMP signaling pathway components, including the PDE4s, varies substantially between tissues, thereby producing an additional level of specificity of action.

Overexpression of WT AIP in rat GH3 and human HeLa cells was shown to reduce forskolin-induced (but not basal) cAMP signaling (Formosa et al. 2013). This effect was observed even in the presence of the general PDE inhibitor IBMX or the selective PDE4 inhibitor rolipram, suggesting that the AIP-PDE interaction is either not required or only partially responsible for the reduction in forskolin-activated cAMP signaling by WT AIP. This may be explained by the fact that AIP, in addition to PDE, interacts with several other proteins. Conversely, knockdown of endogenous AIP resulted in increased cAMP

Published by Bioscientifica Ltd 
Table 1 Reported AIP variants tested in this study.

\begin{tabular}{|c|c|c|c|c|c|}
\hline DNA change & Protein change & SNP id & Control MAF - EVS & Control MAF - EXAC & $\begin{array}{l}\text { Control MAF - } 1000 \\
\text { Genomes Project }\end{array}$ \\
\hline c. $47 \mathrm{G}>\mathrm{A}$ & p.R16H & rs145047094 & 0.254 & 0.1956 & 0.1 \\
\hline c.66_71del & p.G23_E24del & rs267606567 & NO & NO & NO \\
\hline c. $145 \mathrm{G}>\mathrm{A}$ & p.V49M & rs1063385 & 0.0154 & 0.02395 & NO \\
\hline c. $241 C>T$ & p.R81* & rs267606541 & NO & NO & NO \\
\hline c. $308 \mathrm{~A}>\mathrm{G}$ & p.K103R & rs267606548 & NO & NO & NO \\
\hline c. $490 C>T$ & p.Q164* & rs104895073 & NO & NO & NO \\
\hline c.649C>T & p.Q217* & rs267606566 & NO & NO & NO \\
\hline c.713G >A & p.C238Y & rs267606569 & NO & $8.42 \mathrm{e}-04$ & NO \\
\hline c. $721 \mathrm{~A}>\mathrm{G}$ & p.K241E & rs267606573 & NO & $4.212 \mathrm{e}-03$ & NO \\
\hline c.742_744del & p.Y248del & rs267606574 & NO & NO & NO \\
\hline c. $760 \mathrm{~T}>\mathrm{C}$ & p.C254R & NA & NO & NO & NO \\
\hline c.769A >G & p. $1257 \mathrm{~V}$ & rs267606575 & NO & NO & NO \\
\hline$c .811 C>T$ & p.R271W & rs267606579 & NO & NO & NO \\
\hline c. $871 \mathrm{G}>\mathrm{A}$ & p.V291M & NA & NO & NO & NO \\
\hline c. $896 C>T$ & p.A299V & rs148986773 & 0.1002 & 0.04275 & NA \\
\hline c. $910 C>T$ & p.R304* & rs104894195 & NO & $1.715 \mathrm{e}-03$ & NO \\
\hline c. $911 \mathrm{G}>\mathrm{A}$ & p.R304Q & rs104894190 & 0.0693 & 0.1458 & NO \\
\hline
\end{tabular}

The allelic frequencies identified in controls in three public online databases (EVS, ExAC, and 1000 Genomes Project) are shown. MAF frequencies are expressed in percentage.MAF, minor allele frequency; NO, not observed; NA, not applicable.

signaling even in basal conditions (Formosa et al. 2013). Another mechanism suggested for AIP-cAMP interactions via the inhibitory $\mathrm{G}$ protein, $\mathrm{G}$ alpha-i2, as this inhibitory protein had lower level in AIP-deficient cells and human samples, suggesting that failure to inhibit cAMP synthesis through dysfunctional $G$ alpha-i signaling underlies the development of GH-secreting pituitary adenomas in AIP mutation carriers.

In this study, we show that PDE4A4 and PDE4A8 proteins are expressed in human pituitary cells and that their expression is increased in all studied adenoma subtypes. Although prior studies had demonstrated that mRNA transcripts from the PDE4A, PDE4B, and PDE4D genes were present in pituitary cells and adenomas (Persani et al. 2001), these studies did not use immunohistochemistry or immunofluorescence to determine the precise cellular distribution of the isoforms. Interestingly, although PDE4A4 and PDE4A8 are expressed in normal pituitary, they are expressed at higher levels in four different adenoma subtypes. Although the mechanistic effect(s) of this overexpression in adenomas will require further study, this level of PDE4 expression is highly likely to downregulate cAMP signaling pathways and therefore be functionally important.

Whereas differences in normal pituitary tissues obtained through consecutive cuts are expected due to the heterogeneous admixture of several different cell types, adenomas tend to be more uniform as they represent an expansion of a single neoplastic cell representing usually at least $90 \%$ of the adenoma cells. Therefore, we have compared the PDE isoform expression of the different pituitary adenoma subtypes. Whereas PDE4A4 was expressed lower in tumor PRL cells and higher in tumor ACTH cells, the opposite was observed for PDE4A8 isoform. Although these observed results are quite of unknown origin, the differences between isoforms might be related to the evolutionary change from one isoform to the other (Mackenzie et al. 2008). We note that as we had to use a different secondary antibody for the prolactinomas for the PDE4A8 staining, this might have influenced the comparisons.

AIP mutations that predispose to adenomas also impair AIP's ability to interact with PDE4A5 (Leontiou et al. 2008, Igreja et al. 2010). However, AIP interacts with a number of proteins, including survivin and RET (Vargiolu et al. 2009, Kang et al. 2011), both important growth regulatory proteins, with the aryl hydrocarbon receptor (Carver \& Bradfield 1997) and with cAMP signaling pathway members $\mathrm{G}_{\alpha \mathrm{i}}-2$ and $\mathrm{G}_{\alpha 1}-3$ (Tuominen et al. 2015) or PRKAR1A (Schemthaner-Reiter et al. 2014), as well as various chaperones, such as Hsp90 and Hsp70. AIP has also been described as interacting with a different PDE, specifically PDE2A; however, the biochemical and physiologic implications of this observation remain uncertain (de Oliveira et al. 2007, de Oliveira \& Smolenski 2009). Therefore, we need to explore further the potential role of the PDE4A4/5-AIP interaction in the pathogenesis of pituitary tumors. It is possible that PDE4A4/5 in particular, in view of its

Published by Bioscientifica Ltd 
selective interaction with AIP, plays an important role in AIP's tumor suppressor effect; however, it is also possible that increased expression of PDE4 isoforms could be a cellular response to the pro-proliferative effects of AIP loss in pituitary adenoma cells. Finally, it is possible that PDE4A4/5 and other PDE4 isoforms play a role in pituitary processes other than adenoma formation.

Given that oncogenic mutations in AIP attenuate its interaction with PDE4A5, it is possible that PDE4A protein isoforms have important functional roles in pituitary and pituitary adenomas. We have shown previously that AIP inhibits the enzymatic activity of PDE4A5 and therefore acts to increase cAMP levels and activate PKA. Therefore, loss of AIP function should increase the activity of PDE4A4/5, lower cAMP levels, and downregulate PKA. Given that activation, rather than inactivation, of PKA predisposes to somatotroph adenomas ('Introduction' for details), it is most likely that the effect of the AIP mutants on PDE4A4/5 is to generate a compensatory response to tumorigenesis, rather than to promote tumorigenesis. AIP may support the function of inhibitory G-protein $\mathrm{G}_{\alpha \mathrm{i}}-2$ (Tuominen et al. 2015), and the lack of AIP leads to reduced $\mathrm{G}_{\alpha \mathrm{i}}-2$ function, increased adenylyl cyclase activity, and therefore higher cAMP levels. Overactivation of adenylyl cyclase due to gsp mutation, however, is known to produce overexpression of PDE4 as a possible compensatory process (Peverelli et al. 2014). Interaction of AIP and PDE4A4/5 may play a role in this process. However, further functional experiments will be needed to assess this possibility. Interestingly, AIP mutations do not associate with $g s p$ mutations in human adenomas (Hernandez-Ramirez et al. 2015a).

In this study, we assay a number of newly identified AIP variants and show that almost all of them attenuate their interaction with PDE4A5. This is consistent with these variants having an important effect on the biochemical activity of PDE4A5. However, potential anomalies remain, in that two variants deemed pathogenic based on clinical data, K103R and $\Delta \mathrm{G} 23 / \mathrm{E} 24$, have no clear inhibitory effect, or may augment the interaction, as measured by our assay. K103R is a conservative substitution, and both K103R and $\Delta \mathrm{G} 23 / \mathrm{E} 24$ are located outside the TPRs, which are considered to mediate AIP protein's interaction with PDE4A5. It is possible that these mutations might destabilize the AIP protein generally in mammalian cells, as we have shown for several disease-causing missense variants (Hernandez-Ramirez et al. 2015b) or have other effects on AIP and/or PDE4A4/5, which might not be detected by our assay. Further functional studies might provide additional insights into the apparent aberrant effects of these mutants.

Our study has several limitations. Although there is high homology between rat PDE4A5 and human PDE4A4, the human PDE4A4 protein has not been previously shown to interact with AIP. The number of human samples assessed for these protein expressions needs to be increased in the future.

In summary, our data suggest, to our knowledge for the first time, that PDE4A4 and PDE4A8 are expressed in normal human pituitary cells and are overexpressed in all studied pituitary adenoma subtypes. Differences among different adenoma subtypes for PDE4A4 and PDE4A8 isoforms might be related to the rapid evolutionary change from one isoform to the other. We have also tested new AIP mutants for their ability to disrupt the PDE4A5-AIP interaction. Our results suggest a number of further studies. We have yet to evaluate the AIP content, and its correlation with PDE4 isoform expression, in normal and adenomatous pituitary. Determining PDE4 expression in AIP-mutated tumors will possibly also shed light on this field. The physiological function(s) and possible role of PDE4s in counteracting pituitary tumorigenesis require further investigation.

\section{Declaration of interest}

The authors declare that there is no conflict of interest that could be perceived as prejudicing the impartiality of the research reported.

\section{Funding}

This work was supported by the NIH RO1-GM58553 to GBB, the Bolger Prostate Cancer Research Fund (no grant number) to GBB, and the National Cancer Institute of the NIH to the University of Alabama at Birmingham Comprehensive Cancer Center under award number P30 CA013148 (for generation of monoclonal antibodies and DNA sequencing).

\section{Author contribution statement}

G B B and M K developed the idea of the study. G B B provided overall supervision and planned and performed the two-hybrid experiments. A $\mathrm{R} O \mathrm{Jr}$ also provided overall supervision and planned the immunofluorescence studies. M F B and S V B P performed all immunofluorescence studies. G T performed the human variant analysis and, with $\mathrm{M}$ K, provided samples. $\mathrm{M} A \mathrm{~A}$ and $\mathrm{L} S$ generated and characterized the monoclonal antibodies and performed immunoblotting. G B B, M K, and A R O Jr prepared the manuscript.

\section{Acknowledgments}

The content is solely the responsibility of the authors and does not necessarily represent the official views of the National Institutes of Health.

Published by Bioscientifica Ltd 
$M K$ is a member of the Pfizer advisory board and has grant support from Pfizer. A R O Jr was supported by Fapemig and CNPq. The other authors declare no relevant conflicts of interest.

\section{References}

Abecasis GR, Auton A, Brooks LD, DePristo MA, Durbin RM, Handsaker RE, Kang HM, Marth GT \& McVean GA 2012 An integrated map of genetic variation from 1,092 human genomes. Nature 491 56-65. (doi:10.1038/nature11632)

Beckers A, Aaltonen LA, Daly AF \& Karhu A 2013 Familial isolated pituitary adenomas (FIPA) and the pituitary adenoma predisposition due to mutations in the aryl hydrocarbon receptor interacting protein (AIP) gene. Endocrine Reviews 34 239-277. (doi:10.1210/ er.2012-1013)

Beuschlein F, Fassnacht M, Assie G, Calebiro D, Stratakis CA, Osswald A, Ronchi CL, Wieland T, Sbiera S, Faucz FR, et al. 2014 Constitutive activation of PKA catalytic subunit in adrenal Cushing's syndrome. New England Journal of Medicine 370 1019-1028. (doi:10.1056/ NEJMoa1310359)

Bolger G, Michaeli T, Martins T, St John T, Steiner B, Rodgers L, Riggs M, Wigler M \& Ferguson K 1993 A family of human phosphodiesterases homologous to the dunce learning and memory gene product of Drosophila melanogaster are potential targets for antidepressant drugs. Molecular and Cellular Biology 13 6558-6571. (doi:10.1128/ MCB.13.10.6558)

Bolger GB 1998 Molecular genetic approaches. I. Two-hybrid systems. Methods in Molecular Biology 88 101-131.

Bolger GB 2007 Phosphodiesterase isoforms - an annotated list. In Cyclic Nucleotide Phosphodiesterases in Health and Disease, pp 19-31. Eds JA Beavo, SH Francis \& MD Houslay. Boca Raton, FL, USA: CRC Press.

Bolger GB, Conti M \& Houslay MD 2007 Cellular functions of PDE4 enzymes. In Cyclic Nucleotide Phosphodiesterases in Health and Disease, pp. 99-129. Eds JA Beavo, SH Francis \& MD Houslay. Boca Raton, FL, USA: Taylor \& Francis.

Bolger GB, McCahill A, Huston E, Cheung YF, McSorley T, Baillie GS \& Houslay MD 2003a The unique amino-terminal region of the PDE4D5 cAMP phosphodiesterase isoform confers preferential interaction with beta-arrestins. Journal of Biological Chemistry 278 49230-49238. (doi:10.1074/jbc.M303772200)

Bolger GB, McPhee I \& Houslay MD 1996 Alternative splicing of cAMPspecific phosphodiesterase mRNA transcripts. Characterization of a novel tissue-specific isoform, RNPDE4A8. Journal of Biological Chemistry 271 1065-1071. (doi:10.1074/jbc.271.2.1065)

Bolger GB, Peden AH, Steele MR, MacKenzie C, McEwan DG, Wallace DA, Huston E, Baillie GS \& Houslay MD 2003b Attenuation of the activity of the cAMP-specific phosphodiesterase PDE4A5 by interaction with the immunophilin XAP2. Journal of Biological Chemistry 278 33351-33363. (doi:10.1074/jbc.M303269200)

Bolger GB, Rodgers L \& Riggs M 1994 Differential CNS expression of alternative mRNA isoforms of the mammalian genes encoding cAMP-specific phosphodiesterases. Gene 149 237-244. (doi:10.1016/0378-1119(94)90155-4)

Carver LA \& Bradfield CA 1997 Ligand-dependent interaction of the aryl hydrocarbon receptor with a novel immunophilin homolog in vivo. Journal of Biological Chemistry 272 11452-11456. (doi:10.1074/ jbc.272.17.11452)

Christian F, Anthony DF, Vadrevu S, Riddell T, Day JP, McLeod R, Adams DR, Baillie GS \& Houslay MD 2010 p62 (SQSTM1) and cyclic AMP phosphodiesterase-4A4 (PDE4A4) locate to a novel, reversible protein aggregate with links to autophagy and proteasome degradation pathways. Cell Signaling 22 1576-1596. (doi:10.1016/j. cellsig.2010.06.003)

Conti M \& Beavo J 2007 Biochemistry and physiology of cyclic nucleotide phosphodiesterases: essential components in cyclic nucleotide signaling. Annual Review of Biochemistry 76 481-511. (doi:10.1146/annurev.biochem.76.060305.150444)

Daly AF, Vanbellinghen JF, Khoo SK, Jaffrain-Rea ML, Naves LA, Guitelman MA, Murat A, Emy P, Gimenez-Roqueplo AP, Tamburrano G, et al. 2007 Aryl hydrocarbon receptor-interacting protein gene mutations in familial isolated pituitary adenomas: analysis in 73 families. Journal of Clinical Endocrinology and Metabolism 92 1891-1896. (doi:10.1210/jc.2006-2513)

de Oliveira SK, Hoffmeister M, Gambaryan S, Muller-Esterl W, Guimaraes JA \& Smolenski AP 2007 Phosphodiesterase 2A forms a complex with the co-chaperone XAP2 and regulates nuclear translocation of the aryl hydrocarbon receptor. Journal of Biological Chemistry 282 13656-13663. (doi:10.1074/jbc.M610942200)

de Oliveira SK \& Smolenski A 2009 Phosphodiesterases link the aryl hydrocarbon receptor complex to cyclic nucleotide signaling. Biochemical Pharmacology 77 723-733. (doi:10.1016/j. bcp.2008.08.027)

Forlino A, Vetro A, Garavelli L, Ciccone R, London E, Stratakis CA \& Zuffardi O 2014 PRKACB and Carney complex. New England Journal of Medicine 370 1065-1067. (doi:10.1056/NEJMc1309730)

Formosa R \& Vassallo J 2014 cAMP signalling in the normal and tumorigenic pituitary gland. Molecular and Cellular Endocrinology 392 37-50. (doi:10.1016/j.mce.2014.05.004)

Formosa R, Xuereb-Anastasi A \& Vassallo J 2013 Aip regulates cAMP signalling and GH secretion in GH3 cells. Endocrine-Related Cancer 20 495-505. (doi:10.1530/ERC-13-0043)

Francis SH, Blount MA \& Corbin JD 2011 Mammalian cyclic nucleotide phosphodiesterases: molecular mechanisms and physiological functions. Physiological Reviews 91 651-690. (doi:10.1152/ physrev.00030.2010)

Gadelha MR, Trivellin G, Hernandez Ramirez LC \& Korbonits M 2013 Genetics of pituitary adenomas. Frontiers of Hormone Research $\mathbf{4 1}$ 111-140. (doi:10.1159/000345673)

Guarente L 1983 Yeast promoters and LacZ fusions designed to study expression of cloned genes in yeast. Methods in Enzymology 101 181-191. (doi:10.1016/0076-6879(83)01013-7)

Heliovaara E, Raitila A, Launonen V, Paetau A, Arola J, Lehtonen H, Sane T, Weil RJ, Vierimaa O, Salmela P, et al. 2009 The expression of AIP-related molecules in elucidation of cellular pathways in pituitary adenomas. American Journal of Pathology 175 2501-2507. (doi:10.2353/ajpath.2009.081131)

Hernandez-Ramirez LC, Gabrovska P, Denes J, Stals K, Trivellin G, Tilley D, Ferrau F, Evanson J, Ellard S, Grossman AB, et al. 2015a Landscape of familial isolated and young-onset pituitary adenomas: prospective diagnosis in AIP mutation carriers. Journal of Clinical Endocrinology and Metabolism 100 E1242-E1254. (doi:10.1210/jc.2015-1869)

Hernandez-Ramirez LC, Martucci F, Morgan RM, Ferrau F, Trivellin G, Begum F, Tilley D, Ramos-Guajardo N, Iacovazzo D, Prodromou C, et al. $2015 b$ The enhanced proteasomal degradation of AIP mutant proteins is a mechanism for AIP deficiency in AIP mutationassociated pituitary adenomas. Endocrine Reviews OR35-33.

Horvath A, Bertherat J, Groussin L, Guillaud-Bataille M, Tsang K, Cazabat L, Libe R, Remmers E, Rene-Corail F, Faucz FR, et al. 2010 Mutations and polymorphisms in the gene encoding regulatory subunit type 1-alpha of protein kinase A (PRKAR1A): an update. Human Mutation 31 369-379. (doi:10.1002/humu.21178)

Houslay MD 2010 Underpinning compartmentalised cAMP signalling through targeted cAMP breakdown. Trends in Biolochemical Sciences 35 91-100. (doi:10.1016/j.tibs.2009.09.007)

Iacovazzo D, Jose D, Bunce B, Caswell R, Hernandez-Ramirez LC, Caimari F, Ferrau F, Kapur S, Gabrovska P, Dang MN, et al. 2015 X-linked acrogigantism (X-LAG): results from a large cohort of patients with pituitary gigantism. Abstract presented at the ENEA Acromegaly Workshop, Marseilles, France.

Igreja S, Chahal HS, King P, Bolger GB, Srirangalingam U, Guasti L, Chapple JP, Trivellin G, Gueorguiev M, Guegan K, et al. 2010 
Characterization of aryl hydrocarbon receptor interacting protein (AIP) mutations in familial isolated pituitary adenoma families. Human Mutation 31 950-960. (doi:10.1002/humu.21292)

Kang BH, Xia F, Pop R, Dohi T, Socolovsky M \& Altieri DC 2011 Developmental control of apoptosis by the immunophilin aryl hydrocarbon receptor-interacting protein (AIP) involves mitochondrial import of the survivin protein. Journal of Biological Chemistry 286 16758-16767. (doi:10.1074/jbc.M110.210120)

Kinoshita N, Ohkura H \& Yanagida M 1990 Distinct, essential roles of type 1 and $2 \mathrm{~A}$ protein phosphatases in the control of the fission yeast cell division cycle. Cell 63 405-415.

Kreis TE 1986 Microinjected antibodies against the cytoplasmic domain of vesicular stomatitis virus glycoprotein block its transport to the cell surface. EMBO Journal 5 931-941.

Landis CA, Masters SB, Spada A, Pace AM, Bourne HR \& Vallar L 1989 GTPase inhibiting mutations activate the alpha chain of Gs and stimulate adenylyl cyclase in human pituitary tumours. Nature $\mathbf{3 4 0}$ 692-696. (doi:10.1038/340692a0)

Leontiou CA, Gueorguiev M, Van der SJ, Quinton R, Lolli F, Hassan S, Chahal HS, Igreja SC, Jordan S, Rowe J, et al. 2008 The role of the aryl hydrocarbon receptor-interacting protein gene in familial and sporadic pituitary adenomas. Journal of Clinical Endocrinology and Metabolism 93 2390-2401. (doi:10.1210/jc.2007-2611)

Mackenzie KF, Topping EC, Bugaj-Gaweda B, Deng C, Cheung YF, Olsen AE, Stockard CR, High ML, Baillie GS, Grizzle WE, et al. 2008 Human PDE4A8, a novel brain-expressed PDE4 cAMP-specific phosphodiesterase that has undergone rapid evolutionary change. Biochemical Journal 411 361-369. (doi:10.1042/BJ20071251)

Maurice DH, Ke H, Ahmad F, Wang Y, Chung J \& Manganiello VC 2014 Advances in targeting cyclic nucleotide phosphodiesterases. Nature Reviews Drug Discovery 13 290-314. (doi:10.1038/nrd4228)

McPhee I, Yarwood SJ, Scotland G, Huston E, Beard MB, Ross AH, Houslay ES \& Houslay MD 1999 Association with the SRC family tyrosyl kinase LYN triggers a conformational change in the catalytic region of human cAMP-specific phosphodiesterase HSPDE4A4B. Consequences for rolipram inhibition. Journal of Biological Chemistry 274 11796-11810. (doi:10.1074/jbc.274.17.11796)

Morgan RM, Hernandez-Ramirez LC, Trivellin G, Zhou L, Roe SM, Korbonits M \& Prodromou C 2012 Structure of the TPR domain of AIP: lack of client protein interaction with the C-terminal alpha-7 helix of the TPR domain of AIP is sufficient for pituitary adenoma predisposition. PLOS ONE 7 e53339. (doi:10.1371/journal. pone.0053339)

Perry SJ, Baillie GS, Kohout TA, McPhee I, Magiera MM, Ang KL, Miller WE, McLean AJ, Conti M, Houslay MD, et al. 2002 Targeting of cyclic AMP degradation to beta 2 -adrenergic receptors by beta-arrestins. Science 298 834-836. (doi:10.1126/ science.1074683)

Persani L, Borgato S, Lania A, Filopanti M, Mantovani G, Conti M \& Spada A 2001 Relevant cAMP-specific phosphodiesterase isoforms in human pituitary: effect of Gs(alpha) mutations. Journal of Clinical Endocrinology and Metabolism 86 3795-3800. (doi:10.1210/ jcem.86.8.7779)

Peverelli E, Mantovani G, Lania AG \& Spada A 2014 cAMP in the pituitary: an old messenger for multiple signals. Journal of Molecular Endocrinology 52 R67-R77. (doi:10.1530/JME-13-0172)

Ribeiro-Oliveira A Jr, Franchi G, Kola B, Dalino P, Pinheiro SV, Salahuddin N, Musat M, Goth MI, Czirjak S, Hanzely Z, et al. 2008
Protein western array analysis in human pituitary tumours: insights and limitations. Endocrine-Related Cancer 15 1099-1114. (doi:10.1677/ERC-08-0003)

Salpea P \& Stratakis CA 2014 Carney complex and McCune Albright syndrome: an overview of clinical manifestations and human molecular genetics. Molecular and Cellular Endocrinology 386 85-91. (doi:10.1016/j.mce.2013.08.022)

Schemthaner-Reiter MH, Trivellin G, Nesterova M, HernandezRamirez LC, Aflorei ED, delaLuz SM, Stratakis CA \& Korbonits M 2014 Interaction of AIP with the cAMP-dependent protein kinase (PKA) pathway and its role in pituitary tumor formation. Endocrine Reviews 35 PP09-4

Sikorski RS, Boguski MS, Goebl M \& Hieter P 1990 A repeating amino acid motif in CDC23 defines a family of proteins and a new relationship among genes required for mitosis and RNA synthesis. Cell 60 307-317. (doi:10.1016/0092-8674(90)90745-Z)

Steele MR, McCahill A, Thompson DS, MacKenzie C, Isaacs NW, Houslay MD \& Bolger GB 2001 Identification of a surface on the beta-propeller protein RACK1 that interacts with the cAMP-specific phosphodiesterase PDE4D5. Cell Signaling 13 507-513. (doi:10.1016/ S0898-6568(01)00167-X)

Stratakis CA 2013 cAMP/PKA signaling defects in tumors: genetics and tissue-specific pluripotential cell-derived lesions in human and mouse. Molecular and Cellular Endocrinology 371 208-220. (doi:10.1016/j.mce.2013.01.015)

Trivellin G, Daly AF, Faucz FR, Yuan B, Rostomyan L, Larco DO, Schernthaner-Reiter MH, Szarek E, Leal LF, Caberg JH, et al. 2014 Gigantism and acromegaly due to Xq26 microduplications and GPR101 mutation. New England Journal of Medicine 371 2363-2374. (doi:10.1056/NEJMoa1408028)

Tuominen I, Heliovaara E, Raitila A, Rautiainen MR, Mehine M, Katainen R, Donner I, Aittomaki V, Lehtonen HJ, Ahlsten M, et al. 2015 AIP inactivation leads to pituitary tumorigenesis through defective Galphai-cAMP signaling. Oncogene 34 1174-1184. (doi:10.1038/onc.2014.50)

Vargiolu M, Fusco D, Kurelac I, Dirnberger D, Baumeister R, Morra I, Melcarne A, Rimondini R, Romeo G \& Bonora E 2009 The tyrosine kinase receptor RET interacts in vivo with aryl hydrocarbon receptorinteracting protein to alter survivin availability. Journal of Clinical Endocrinology and Metabolism 94 2571-2578. (doi:10.1210/jc.20081980)

Vierimaa O, Georgitsi M, Lehtonen R, Vahteristo P, Kokko A, Raitila A, Tuppurainen K, Ebeling TM, Salmela PI, Paschke R, et al. 2006 Pituitary adenoma predisposition caused by germline mutations in the AIP gene. Science 312 1228-1230. (doi:10.1126/ science.1126100)

Weiner MP, Costa GL, Schoettlin W, Cline J, Mathur E \& Bauer JC 1994 Site-directed mutagenesis of double-stranded DNA by the polymerase chain reaction. Gene 151 119-123. (doi:10.1016/03781119(94)90641-6)

Willoughby D \& Cooper DM 2007 Organization and Ca2+ regulation of adenylyl cyclases in cAMP microdomains. Physiological Reviews $\mathbf{8 7}$ 965-1010. (doi:10.1152/physrev.00049.2006)

Yarwood SJ, Steele MR, Scotland G, Houslay MD \& Bolger GB 1999 The RACK1 signaling scaffold protein selectively interacts with the cAMP-specific phosphodiesterase PDE4D5 isoform. Journal of Biological Chemistry 274 14909-14917. (doi:10.1074/ jbc.274.21.14909)

Received in final form 31 March 2016 Accepted 18 April 2016
(C) 2016 Society for Endocrinology Printed in Great Britain
Published by Bioscientifica Ltd. 